\title{
ARTICLE
}

\section{Micromorphological, anatomical and molecular study of Hedera species (Araliaceae) in Iran}

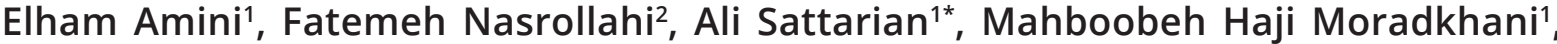 \\ Sohrab Boozarpour ${ }^{1}$, Meisam Habibi ${ }^{1}$
}

'Department of Biology, Faculty of Sciences, Gonbad Kavous University, Gonbad, Iran.

2Department of Biology, Faculty of Sciences, University of Qom, Qom, Iran.

\begin{abstract}
Hedera, with 12 extant species, is a genus of evergreen climbers native to Europe, north Africa, and south Asia. In this study, the micromorphological, anatomical structure and molecular evidences of 11 populations from two species of Hedera $(H$. helix and $H$. pastuchovii) have been considered to evaluate the relationships in Hedera. In total, seven quantitative and qualitative characters of pollen were selected and measured. Based on this study, the anticlinal wall and surface sculpturing of seed support for separation of two species of Hedera. Micromorphology of epidermis illustrated two types of epidermal cells: puzzle-shaped and polygonal cells. Using nuclear (nrDNA ITS) marker, we reconstructed phylogenetic relationships within two species of Hedera. This data set was analyzed by phylogenetic methods including Bayesian inference, maximum likelihood, and maximum parsimony. In phylogenetic analyses, all members of two species formed a well-supported clade (PP $=1 ; \mathrm{ML} / \mathrm{BS}=100 / 100)$ and divided into two major clades ( $A$ and B). Neighbor Net diagram demonstrated separation of the studied populations. The results showed that these taxa differ in taxonomically important micromorphological, anatomical and molecular characteristics and these data provide reliable evidence for separation of these two species.
\end{abstract}

Acta Biol Szeged 63(2):91-101 (2019)

\section{KEY WORDS}

anatomical structure Hedera

Neighbor Net

nrDNA ITS

pollen

seed

\author{
ARTICLE INFORMATION \\ Submitted \\ 18 July 2019. \\ Accepted \\ 26 November 2019 \\ *Corresponding author \\ E-mail: sattarian.ali@gmail.com
}

\section{Introduction}

Hedera L. (Araliaceae), with 12 extant species, is a genus of evergreen climbers native to Europe, north Africa, and south Asia (Vargas et al. 1999; Grivet and Petit 2002; Ackerfield and Wen 2003; Valcárcel et al. 2003a; Valcárcel and Vargas 2010; Valcárcel et al. 2014) and occupies forest under stories and riparian vegetation in temperate latitudes throughout Europe, N Africa and Asia (Meusel et al. 1965; Mabberley 1997). Hedera is a considerable element in Asian and European woodlands, comprising a large component of the forest understory.

The taxonomical treatments of Hedera published through the second half of the 20th century recognized between three and 19 species (Seemann 1868; Tobler 1912; Lawrence and Schulze 1942; Pojarkova 1951). More recently authors have accepted the 12 entities proposed by McAllister and Rutherford (McAllister 1982, 1988; Rutherford 1984, 1989; McAllister and Rutherford 1990; Rutherford et al. 1993) with slight changes at the subspecies level (Ackerfield and Wen 2002; Valcárcel 2008; Valcárcel and Vargas 2010). Since McAllister and Ruth- erford's treatment, the identification and delimitation of Hedera species have mainly been based on a combination of trichome morphology (stellate-multiangulate, stellaterotate, and scale like hairs; Seemann 1868; Lum and Maze 1989; McAllister and Rutherford 1990; Ackerfield and Wen 2002; Valcárcel and Vargas 2010), juvenile leaf morphology (from entire to 3-7 lobate; Rutherford et al. 1993; Ackerfield and Wen 2002; Valcárcel 2008; Valcárcel and Vargas 2010), and ploidy level (from 29 to 89; Vargas et al. 1999).

Micromorphological characters are good diagnostic value to recognize many taxa, fundamentally in the species level. The pollen morphological analysis is successfully used as an additional document for delimitation of the taxa (Amini et al. 2018; 2019). Van Helvoort and Punt (1984) in the Northwest European Pollen Flora mentioned that pollen class of Hedera is 3-zonocolporate, sub erect to semi-erect with reticulate ornamentation. In Scandinavian pollen flora, apocolpium diameter of pollen grains is about $10 \mathrm{p}$. Colpi is narrow; exine thickness is about $2.5 \mathrm{p}$ and sometimes distinctly thicker at poles (Erdtman et al. 1961).

The anatomical structure of some Hedera species 
show that anatomical features can be valuable in species delimitation especially about similar taxa. Taxonomic value of epidermis anatomical features is well documented in botanical literature (Dilcher 1974; Metcalf 1985). Savulescu and Luchian (2009) studied the diagnostic value of Hedera epidermis and illustrated that epidermis is made up of only one cells layer with polygonal cells with thin lateral walls and corrugated.

Molecular data can provide extra criteria for systematic classification of the species studied that have been only based on the morphological characters (Chase et al. 1993). Nuclear ribosomal DNA provides highly informative variation that has been used to infer phylogenetic relationships in angiosperms. Its value stems from the high rate of divergence at the specific, and sometimes, the populational level (Baldwin 1993; Vargas et al. 1998; Vargas et al. 1999). The internal transcribed spacer(ITS) is the region of the $18 \mathrm{~S}-5.8 \mathrm{~S}-26 \mathrm{~S}$ nuclear ribosomal cistron (Baldwin et al. 1995) and have often been used for inferring phylogeny at the generic and infrageneric relationships of genera (e.g., Baldwin 1992; Baldwin et al. 1995; Amini et al. 2018; Nasrollahi et al. 2019). Previous molecular and cytogenetic studies identified two main centers of diversity for Hedera, the eastern and western parts of the Mediterranean region. Molecular phylogenetic reconstructions of 37 of the 41 Araliaceae genera clearly placed Hedera within the Asian Palmate group (Lowry et al. 2001; Wen et al. 2001; Valcárcel et al. 2003; Plunkett et al. 2004).

Vargas et al. (1999) applied variation in chromosome number and internal transcribed sequences (ITS) of nrDNA to infer phylogenetic relationships of a wide range of Hedera species. Polyploidy was found to be frequent in Hedera, with diploid, tetraploid, hexaploid and octoploid populations being detected. Valcárcel and Vargas (2012) studied the phylogenetic reconstruction of key traits in the evolution of ivies (Hedera L.) and the analyses of the nrDNA ITS and plastid trnT-L sequences revealed multiple connections between the Mediterranean region and Asia and suggest recurrent colonization between these two areas. Valcárcel et al. (2014) studied the origin of the early differentiation of ivies (Hedera) and the radiation of the Asian Palmate group (Araliaceae). Genome incongruence and hard nuclear and plastid basal polytomies are detected for the Asian Palmate group where the lineage of Hedera is placed.

Despite ecological impacts and economic significance of Hedera to the horticultural industry, the taxonomy of Hedera is controversial and historical relationships are poorly defined.

The specific goals of this study were as follows: (1) to examine pollen and seed micro-morphological characters that could be useful for the diagnosis of taxa; (2) to determine the patterns of variation in epidermal characteristics in two species; (3) to evaluate the affinities and relationships of taxa; (4) to investigate molecular properties of Hedera in Iran.

\section{Materials and Methods}

\section{Morphological methods}

In the present study, 11 populations of two Hedera species were collected from different locations in North Iran and preserved in the Gonbad Kavous University Herbarium (GKUH). Identification of populations was carried out based on Flora Iranica (Browicz 1973). The list of voucher populations and details of localities are given in Table 1.

Palynological studies on pollens of $H$. helix L. and $H$. pastuchovii Woron. Ex Grossh was made using a light microscope (LM) (Olympus, Vanox AHBS3) with a DP12 digital camera and a scanning electron microscope (SEM; Tescan, Vega-3 $L M U$ ). For SEM investigations, the pollen grains were transferred directly to double-sided tape affixed stubs and were sputter-coated with gold plates. The applied terminology based on Punt et al. (2007). For LM studies, the samples were acetolyzed following Erdtman's technique (Erdtman 1952). The pollen samples were obtained mostly from freshly collected herbarium populations. The measurements were based on at least 30 pollen grains per population. The characters of pollen grains of the studied Hedera species are summarized in Table 2.

In order to detect significant differences in the studied characters among the investigated species, an analysis of variance (ANOVA) was done. To determine the species relationships, we have used cluster analysis and principal component analysis (PCA; Ingrouille 1986). For multivariate analysis, the mean of the quantitative characters was calculated. Qualitative characters were coded as binary or multistate. Variables were standardized for multivariate statistical analysis. Average taxonomic distances and squared Euclidean distances were calculated as dissimilarity coefficient in the cluster analysis of pollen data. In order to determine the most variable characters among the studied species, factor analysis based on principal components analysis was performed. SPSS ver. 20 and PAST ver. 2.17c (2013) softwares were performed for statistical analysis.

Seeds of the two species of Hedera were taken from herbarium samples: before mounted directly on aluminum stubs using double-sided adhesive, they were examined under a stereomicroscope to ensure the normal size and development. After having been coated with a thin layer (ca. $25 \mathrm{~nm}$ ) of gold they were analyzed using a SEM (Tescan, Vega-3 LMU) at an accelerating voltage of $15-22 \mathrm{kV}$ at 
Table 1. List of species used in the study along with localities and vouchers.

\begin{tabular}{llc}
\hline Taxa & Collection data & $\begin{array}{c}\text { GenBank } \\
\text { accession no./ITS }\end{array}$ \\
\hline H. helix L. & Tehran: Research Institute of Forests and Rangelands, Haji Moradkhani, 803298, GKUH & LC508655 \\
H. helix & Golestan: Gonbad Kavous, Haji Moradkhani, 803297, GKUH & LC508656 \\
H. helix & Fars: Kamfiruz, Tang-e Bostan, Haji Moradkhani, 803299, GKUH & LC508657 \\
H. pastuchovii Woron. Ex Grossh. & Golestan: Gorgan, Naharkhoran forest, Haji Moradkhani, 803270, GKUH & LC508658 \\
H. pastuchovii & Golestan: Gorgan, Ziarat village, Haji Moradkhani, 803273, GKUH & LC508659 \\
H. pastuchovii & Gilan: Gisum forest, Haji Moradkhani, 803289, GKUH & LC508660 \\
H. pastuchovii & Gilan: Fuman forest, Mirmahaleh, Haji Moradkhani, 803292, GKUH & LC508661 \\
H. pastuchovii & Gilan: Somee Sara, Haji Moradkhani, 803290, GKUH & LC508662 \\
H. pastuchovii & Mazandaran: Nur forest, Haji Moradkhani, 803279, GKUH & LC508663 \\
H. pastuchovii & Mazandaran: Najardeh, Haji Moradkhani, 803278, GKUH & LC508663 \\
H. pastuchovii & Mazandaran: Sari, Haji Moradkhani, 803295, GKUH & LC508665 \\
Trevesia palmata Vis. & GenBank & KF591487 \\
Brassaiopsis mitis Clarke & GenBank & AY304801 \\
\hline
\end{tabular}

GKUH: Gonbad Kavous University Herbarium

Research Institute of Razi (Tehran, Iran). For recording gross morphology and size parameters, at least 10 seeds were measured.

\section{Anatomical methods}

All materials were boiled for $15 \mathrm{~min}$, and then fixed in Carnoy solution (alcohols to acetic acid in proportion 3:1). The epidermis was separated with $\mathrm{H}_{2} \mathrm{O}_{2}$ and acetic acid (1:1), in order to prepare the leaves. Materials were kept warm in a tube with previous lotions (the above-mentioned solutions) for 4 hours, then the leaves were cleaned. After cleaning, the materials were washed in distilled water. Epidermis separation followed. Epidermal samples were stained with $2 \%$ aceto-carmine and were mounted on microscopic glass slides. Slide sections were studied and photographed with the help of an Olympus light microscope by using a Olympus DP12 Digital Camera. Some characters (stomata length/weight, number of stomata, number of epidermal cells) were measured with Image Tools ver. 3.0 and Axio Vision 4.8. (Table 5).

\section{Molecular methods}

\section{Taxon sampling}

Sampling includes plants from 3 populations of $H$. helix and 8 populations $H$. pastuchovii were chosen as ingroup for nrDNA ITS. Trevesia palmata Vis. and Brassaiopsis mitis Clarke were chosen as outgroup following previous molecular phylogenetic studies (Wen et al. 2001). A list of all the taxa used in this study and the sources,

Table 2. Pollen morphological characters for the examined taxa of Hedera.

\begin{tabular}{|c|c|c|c|c|c|c|c|}
\hline Taxon & $\begin{array}{l}\text { Length of polar } \\
\text { axis }(\mu \mathrm{m} \pm S D)\end{array}$ & $\begin{array}{l}\text { Length of equatorial } \\
\text { axis }(\mu \mathrm{m} \pm S D)\end{array}$ & $P / E$ & Shape & $\begin{array}{l}\text { Colpus length } \\
(\mu \mathrm{m} \pm \mathrm{SD})\end{array}$ & $\begin{array}{l}\text { Colpus width } \\
(\mu \mathrm{m} \pm \mathrm{SD})\end{array}$ & Ornamentation \\
\hline H. helix & $21.55 \pm 1.48$ & $18.77 \pm 0.43$ & 1.14 & Subprolate & $18.60 \pm 0.12$ & $1.23 \pm 0.05$ & Microperforate \\
\hline H. helix & $21.05 \pm 1.17$ & $19.65 \pm 0.27$ & 1.07 & Subprolate & $18.80 \pm 0.09$ & $1.14 \pm 0.01$ & Microperforate \\
\hline H. helix & $22.05 \pm 1.17$ & $18.65 \pm 0.27$ & 1.07 & Subprolate & $17.80 \pm 0.09$ & $1.25 \pm 0.01$ & Microperforate \\
\hline H. pastuchovii & $38.75 \pm 2.03$ & $27.37 \pm 0.32$ & 1.41 & Prolate & $24.70 \pm 0.15$ & $2.05 \pm 0.09$ & Reticulate \\
\hline H. pastuchovii & $33.65 \pm 1.19$ & $24.43 \pm 0.35$ & 1.37 & Prolate & $25.16 \pm 0.16$ & $2.74 \pm 0.04$ & Reticulate \\
\hline H. pastuchovii & $36.79 \pm 1.18$ & $25.67 \pm 0.29$ & 1.43 & Prolate & $23.96 \pm 0.07$ & $2.63 \pm 0.01$ & Reticulate \\
\hline H. pastuchovii & $38.73 \pm 1.31$ & $27.35 \pm 0.34$ & 1.41 & Prolate & $24.36 \pm 0.21$ & $2.85 \pm 0.03$ & Reticulate \\
\hline H. pastuchovii & $34.65 \pm 1.36$ & $22.43 \pm 0.31$ & 1.54 & Prolate & $25.10 \pm 0.16$ & $2.70 \pm 0.01$ & Reticulate \\
\hline H. pastuchovii & $36.75 \pm 0.41$ & $24.47 \pm 0.44$ & 1.50 & Prolate & $23.98 \pm 0.12$ & $2.34 \pm 0.07$ & Reticulate \\
\hline H. pastuchovii & $37.64 \pm 0.34$ & $25.35 \pm 0.17$ & 1.48 & Prolate & $25.49 \pm 0.28$ & $2.45 \pm 0.04$ & Reticulate \\
\hline H. pastuchovii & $35.44 \pm 0.38$ & $23.65 \pm 0.28$ & 1.49 & Prolate & $25.70 \pm 0.19$ & $2.78 \pm 0.06$ & Reticulate \\
\hline
\end{tabular}


voucher information and GenBank accession numbers are given in Table 1.

\section{DNA extraction, $P C R$ and sequencing}

Total genomic DNA was extracted from dried leaf materials deposited in Gonbad Kavous University Herbarium (GKUH), using Kit method. The nrDNA ITS (Nuclear ribosomal DNA Internal Transcribed Spacer) region was amplified using the primers ITS5m of Sang et al. (1995) and ITS4 of White et al. (1990). PCR amplification of the DNA regions followed procedures described in detail by Naderi Safar et al. (2014). The quality of PCR products was checked by electrophoresis in $1 \%$ agarose gels in $1 \times$ TAE ( $\mathrm{pH}$ 8) buffer and were photographed with an UV gel documentation system (UVItec, Cambridge, UK). PCR products along with the same primers were sent for Sanger sequencing at Macrogen (Seoul, South Korea) through Pishgam (Tehran-Iran).

\section{Sequence alignment}

Single dataset was aligned using the web-based version of MUSCLE (Edgar 2004, at http://www.ebi.ac.uk/Tools/ $\mathrm{msa} / \mathrm{muscle} /$ ) under default parameters followed by manual adjustment. The alignment of dataset required the introduction of numerous single and multiple-base indels (insertions/deletions). Positions of indels were treated as missing data for the ITS dataset.

\section{Phylogenetic inferences}

\section{Parsimony method}

Maximum parsimony (MP) analyses were conducted using PAUP* version 4.0a157 (Swofford 2002). The heuristic search option was employed for nuclear dataset using tree bisection-reconnection (TBR) branch swapping, with 1000 replications of random addition sequence and an automatic increase in the maximum number of trees. Uninformative characters were excluded from the analyses. Branch support values (MPBS) were estimated using a full heuristic search with 1000 bootstrap replicates (Felsenstein 1985) each with simple addition sequence.

\section{Likelihood method}

Maximum likelihood (ML) analyses were carried out using the RAxML-HPC2 on XSEDE (8.2.8) at the CIPRES Science Gateway. Bootstrap values (LBS) were calculated in RAxML-HPC2 based on 1000 replicates with one search replicate per bootstrap replicate.

\section{Bayesian inference}

For Bayesian inference (BI) analyses, models of sequence evolution were selected using the program MrModeltest version 2.3 (Nylander 2004) based on the Akaike information criterion (AIC) (Posada and Buckley 2004). This program indicated a GTR $+\mathrm{G}$ model for nrDNA ITS. BI analyses were performed using MrBayes version 3.2 (Ronquist et al. 2012) on the CIPRES Science Gateway (Cyber infrastructure for Phylogenetic Research cluster) (Miller et al. 2010, https://www.phylo.org) for the dataset. Bayesian analyses were performed, with default priors (uniform priors) and the best-fit model of sequence evolution for dataset, with two runs of ten million generations and four simultaneous chains (one cold and three heated with a heating parameter of 0.2 ), by saving trees every 100 generations. The trees sampled after discarding $25 \%$ as "burn-in" were collected to build a $50 \%$ majority rule consensus phylogram were used to calculate posterior probability values (PP). Tree visualization was carried out using Tree View version 1.6.6 (Page 2001).

\section{Phylogenetic networks}

NeighborNet (NN) a distance-based network construction method (Bryant and Moulton 2004) was implemented in SplitsTree4, version 4.14.4 (Huson and Bryant 2006) based on the uncorrected $p$-distance between populations that was calculated from the ITS sequence data. The ITS matrice was modified prior to analysis by excluding the outgroup.

\section{Results}

\section{Pollen morphology}

The pollen grains of the studied species revealed some variations and separated two species of Hedera. All palynological structures and measurements for the examined species concerning pollen type from polar view, polar $(\mathrm{P})$ and equatorial (E) measurements, $\mathrm{P} / \mathrm{E}$ ratio, colpus length and width, pollen shape and exine ornamentation were shown in Table 2. Selected SEM micrographs of the pollens and their surfaces are shown in Fig. 1. Generally, type of pollen grain aperture is observed tricolporate among studied species (Fig. 1). Length of polar and equatorial axis were found useful in separating two species. Polar axis $(\mathrm{P})$ length of pollen grains ranging from the smallest size for H. helix $(21.05 \mu \mathrm{m})$ to the largest size for $H$. pastuchovii $(38.75 \mu \mathrm{m})$. Equatorial axis (E) length of pollen grains ranged from the smallest size in H. helix $(18.65 \mu \mathrm{m})$ to the largest size in $H$. pastuchovii $(27.37 \mu \mathrm{m})$. The shape classes are based on the ratio between the length of polar axis (P) and equatorial diameter (E) (Erdtman 1952). The $\mathrm{P} / \mathrm{E}$ ratio ranged from 1.07 to 1.54 , therefore the pollen shape is subprolate in H. helix but prolate in H. pastuchovii. The ornamentation of tectum is microperforate in $H$. helix (Fig. 1B) and is reticulate in H. pastuchovii (Fig. 1C).

In order to define the diagnostic value of pollen grains 


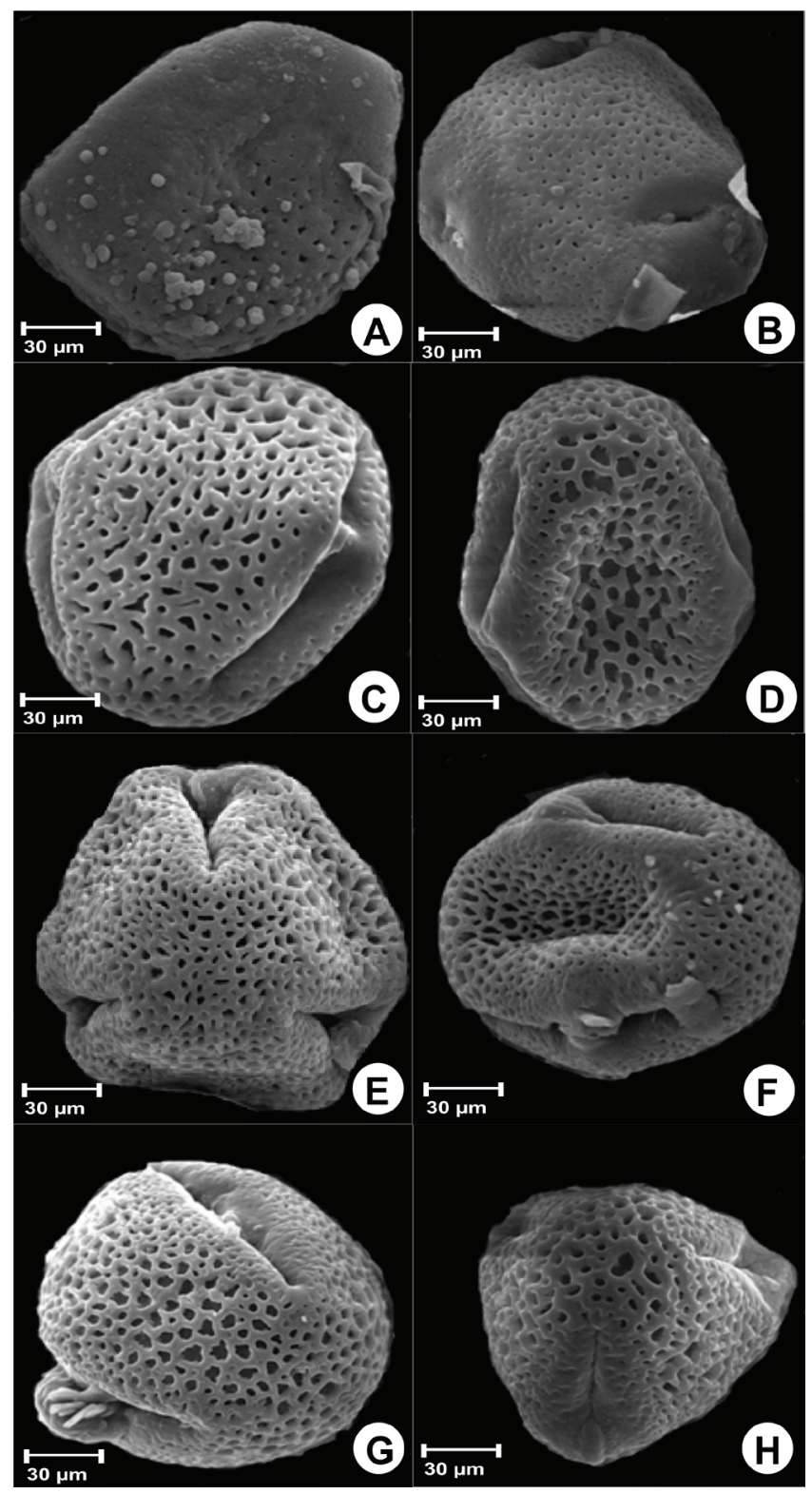

Figure 1. Scanning electron micrographs (SEM) of pollen surface in H. helix and H. pastuchovii. (A, B) H. helix, (C, D) H. pastuchovii, (E, F) H. pastuchovii, and $(\mathrm{G}, \mathrm{H}) \mathrm{H}$. pastuchovii.

in species delimitations in studied Hedera species, cluster analysis by Ward's method was performed on the base of seven qualitative and quantitative features (Fig. 2). Ward's dendrogram showed two main clusters (Fig. 2). First cluster composed of populations of $H$. helix. Second cluster composed of two subclusters and contained populations of $H$. pastuchovii. Principal component analysis revealed that there were two components providing more than $76 \%$ of total observed variation in studied pollen grains. Studying the component loading was evident that shape and ornamentation of tectum are most important features

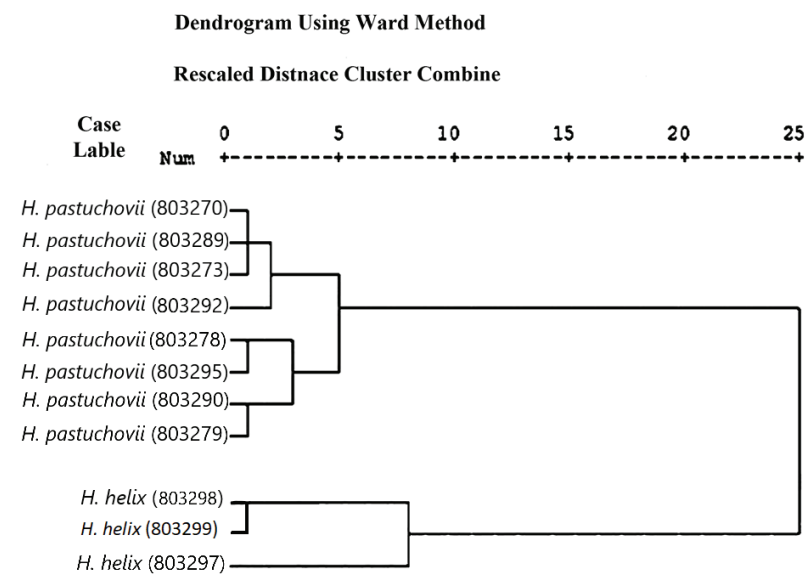

Figure 2. Cluster analysis (Ward's method) based on pollen features of Hedera.

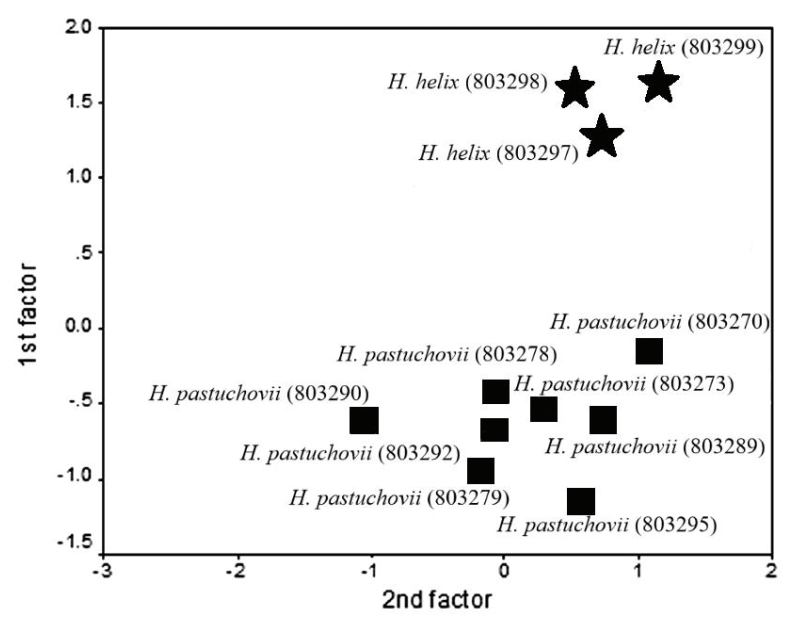

Figure 3. PCA plot of Hedera species based on observed pollen data.

in the first factor and $\mathrm{P} / \mathrm{E}$ ratio and length of polar axis are most significant in the second factor. PCA confirmed the results of cluster analysis by Ward's method based on qualitative and quantitative features of pollen grains (Fig. 3).

\section{Seed shape and size}

Taxonomic importance of selected seed features in the examined taxa are summarized in Table 3. Selected SEM micrographs of the seeds and their surfaces are shown in Fig. 4. Seed size differs significantly between two species of Hedera. Generally, seeds of $H$. helix are slightly smaller than those of $H$. pastuchovii. The length of the seeds ranged from $3.18 \mathrm{~mm}$ in $H$. helix to $5.45 \mathrm{~mm}$ in $H$. pastuchovii (column 2 in Table 3), and their width varied from 2.08 $\mathrm{mm}$ in H. helix to $4.87 \mathrm{~mm}$ in $H$. pastuchovii (column 3 in Table 3). In general, the seeds shapes have been observed 
Amini et al.

Table 3. Some diagnostic seed micromorphological features in species of Hedera.

\begin{tabular}{|c|c|c|c|c|c|c|}
\hline Taxon & Length $(\mathrm{mm})$ & Width $(\mathrm{mm})$ & Length/Width & Shape & Anticlinal wall & Sculpturing \\
\hline H. helix & $3.40 \pm 0.01$ & $2.08 \pm 0.04$ & 1.63 & Almond to Circular & Shallowly undulate & Smooth \\
\hline H. helix & $3.38 \pm 0.04$ & $2.18 \pm 0.05$ & 1.55 & Almond to Circular & Shallowly undulate & Smooth \\
\hline H. helix & $3.18 \pm 0.02$ & $2.28 \pm 0.04$ & 1.39 & Almond to Circular & Shallowly undulate & Smooth \\
\hline H. pastuchovii & $5.15 \pm 0.06$ & $4.28 \pm 0.04$ & 1.20 & Almond to Circular & Deeply undulate & Polygonal \\
\hline H. pastuchovii & $5.25 \pm 0.02$ & $4.47 \pm 0.06$ & 1.17 & Almond to Circular & Deeply undulate & Polygonal \\
\hline H. pastuchovii & $5.15 \pm 0.03$ & $4.87 \pm 0.05$ & 1.05 & Almond to Circular & Deeply undulate & Polygonal \\
\hline H. pastuchovii & $5.30 \pm 0.02$ & $4.37 \pm 0.06$ & 1.21 & Almond to Circular & Deeply undulate & Polygonal \\
\hline H. pastuchovii & $5.05 \pm 0.01$ & $3.67 \pm 0.07$ & 1.37 & Almond to Circular & Deeply undulate & Polygonal \\
\hline H. pastuchovii & $5.18 \pm 0.04$ & $4.27 \pm 0.06$ & 1.21 & Almond to Circular & Deeply undulate & Polygonal \\
\hline H. pastuchovii & $5.20 \pm 0.01$ & $4.17 \pm 0.06$ & 1.24 & Almond to Circular & Deeply undulate & Polygonal \\
\hline H. pastuchovii & $5.45 \pm 0.07$ & $4.16 \pm 0.02$ & 1.31 & Almond to Circular & Deeply undulate & Polygonal \\
\hline
\end{tabular}

almond to circular in two species (Figs. $4 \mathrm{~A}$ and $4 \mathrm{G}$ ).

\section{Seed Sculpturing}

In terms of exomorphology, the surface of the seed in H. helix is smooth and the anticlinal walls are shallowly undulate (Figs. 4B, 4D and 4F). In H. pastuchovii, the seeds have a polygonal surface and the anticlinal walls are observed deeply undulate (Figs. 4H, 4J and 4L).

\section{Epidermal cell description}

Epidermal and stomata characters of the leaves, such as cell shape, anticlinal wall patterns, stomata index, density, size, and types were examined (Table 4). There were two types of epidermal cells: puzzle-shaped and polygonal cells could be seen, and anticlinal walls have been observed the wavy and sinuous shapes. There are polygonal cells with wavy anticlinal walls on the adaxial leaf side of $H$. helix (Figs. 5A). Puzzle-shaped cells with sinuous cell walls were seen in H. pastuchovii (Figs 5C, $5 \mathrm{E}$ and $5 \mathrm{G}$ ). Abaxial leaf epidermal cells were irregular, with wavy anticlinal walls in $H$. helix (Fig. 5B). No stomata were seen on the adaxial surface of the examined species (Figs. 5A and 5C). All studied species had stomata on the abaxial leaf surface. All treated populations were of the anemocytic stomata type (Figs. 5B and 5D). The largest in size stomata were observed in $H$. pastuchovii (Figs. $5 \mathrm{~F}$ and $5 \mathrm{H}$ ) and the smallest were observed in H. helix (Fig. 5B). The maximum stomatal index and density were registered in H. helix (Table 4).

Table 4. Leaf epidermal anatomical features of Hedera.

\begin{tabular}{|c|c|c|c|c|c|c|c|c|}
\hline \multicolumn{4}{|c|}{ Adaxial epidermis } & \multicolumn{5}{|c|}{ Abaxial epidermis } \\
\hline Taxon & Cell shape & Anticlinal walls & $\begin{array}{l}\text { Stomatal ap- } \\
\text { paratus cell }\end{array}$ & $\begin{array}{l}\text { Anticlinal } \\
\text { walls }\end{array}$ & $\begin{array}{l}\text { Stomata index } \\
\left(\mathrm{mm}^{2}\right)\end{array}$ & $\begin{array}{l}\text { Stomata density } \\
\left(\mathrm{mm}^{2}\right)\end{array}$ & $\begin{array}{l}\text { Stomata size } \\
(\mu \mathrm{m})\end{array}$ & Stomata type \\
\hline H. helix & Pol & Wa & - & Irr & $7 \pm 0.01$ & $191.70 \pm 2.3$ & $49.62 \times 42.24$ & Anemocytic \\
\hline H. helix & Pol & Wa & - & Irr & $9 \pm 0.04$ & $198.50 \pm 4.3$ & $46.31 \times 40.43$ & Anemocytic \\
\hline H. helix & Pol & Wa & - & Irr & $7 \pm 0.02$ & $189.32 \pm 3.3$ & $52.41 \times 46.34$ & Anemocytic \\
\hline H. pastuchovii & Puz & $\operatorname{Sin}$ & - & $\operatorname{Sin}$ & $11 \pm 0.09$ & $120.25 \pm 2.1$ & $71.32 \times 66.24$ & Anemocytic \\
\hline H. pastuchovii & Puz & $\operatorname{Sin}$ & - & $\operatorname{Sin}$ & $13 \pm 0.02$ & $107.18 \pm 1.4$ & $62.45 \times 53.14$ & Anemocytic \\
\hline H. pastuchovii & Puz & $\operatorname{Sin}$ & - & $\operatorname{Sin}$ & $12 \pm 0.03$ & $132.23 \pm 1.2$ & $61.41 \times 54.32$ & Anemocytic \\
\hline H. pastuchovii & Puz & $\operatorname{Sin}$ & - & $\operatorname{Sin}$ & $10 \pm 0.04$ & $121.16 \pm 3.2$ & $72.43 \times 65.30$ & Anemocytic \\
\hline H. pastuchovii & Puz & $\operatorname{Sin}$ & - & $\operatorname{Sin}$ & $12 \pm 0.01$ & $95.19 \pm 2.5$ & $65.25 \times 51.20$ & Anemocytic \\
\hline H. pastuchovii & Puz & $\operatorname{Sin}$ & - & $\operatorname{Sin}$ & $10 \pm 0.04$ & $108.14 \pm 4.2$ & $60.42 \times 52.33$ & Anemocytic \\
\hline H. pastuchovii & Puz & $\operatorname{Sin}$ & - & $\operatorname{Sin}$ & $13 \pm 0.07$ & $135.28 \pm 1.7$ & $73.40 \times 62.30$ & Anemocytic \\
\hline H. pastuchovii & Puz & $\operatorname{Sin}$ & - & $\operatorname{Sin}$ & $12 \pm 0.09$ & $140.19 \pm 3.5$ & $65.41 \times 55.34$ & Anemocytic \\
\hline H. pastuchovii & Puz & $\operatorname{Sin}$ & - & $\operatorname{Sin}$ & $14 \pm 0.04$ & $153.14 \pm 4.2$ & $72.35 \times 66.30$ & Anemocytic \\
\hline H. pastuchovii & Puz & $\operatorname{Sin}$ & - & $\operatorname{Sin}$ & $13 \pm 0.03$ & $109.24 \pm 6.5$ & $66.40 \times 58.34$ & Anemocytic \\
\hline
\end{tabular}

Irr: Irregular; Pol: Polygonal; Puz: Puzzle-shaped; Sin: Sinuous; Wa: Wavy. 


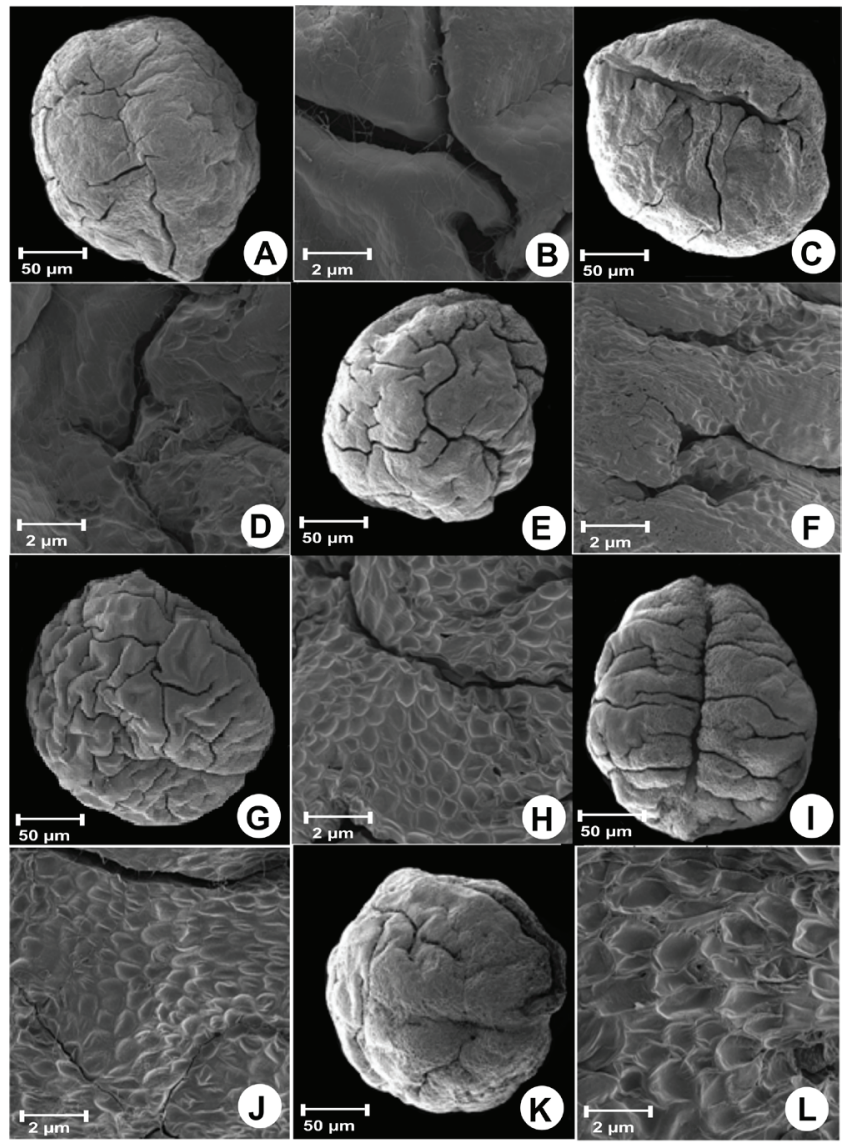

Figure 4. Scanning electron micrographs (SEM) of seed surface in $H$. helix and $H$. pastuchovii. For each taxon, the first micrograph shows the outline of the seed indicating its general shape, and the second micrograph is a close view of the seed surface.(A, B) $H$. helix, (C, D) $H$. helix, (E, F) H. helix, (G, H) H. pastuchovii, (I, J) H. pastuchovii, and (K, L) H. pastuchovii.

\section{Phylogenetic analysis}

Detailed information about alignment characteristics, selected model of nucleotide substitution, as well as tree statistics from the single analysis of the nrDNA ITS region, are summarized in Table 5 . The aligned nrDNA ITS matrix comprises 602 characters. The maximum parsimony, maximum likelihood and Bayesian analyses of the nrDNA ITS produced congruent trees and gave similar results. All members of this genus form a wellsupported clade $(\mathrm{PP}=1, \mathrm{ML} / \mathrm{BS}=100 / 100)$ (Fig. 6). The Hedera clade is composed of two clades. Clade A includes the populations of $H$. helix $(\mathrm{PP}=0.96, \mathrm{ML} / \mathrm{BS}=98 / 100)$ and the clade $\mathrm{B}(\mathrm{PP}=0.95, \mathrm{ML} / \mathrm{BS}=100 / 100)$ comprises the rest of the species of Hedera (H. pastuchovii) (Fig. 6).

\section{Phylogenetic networks}

The NeighborNet diagram (Fig. 7) revealed almost complete separation of the studied populations within the

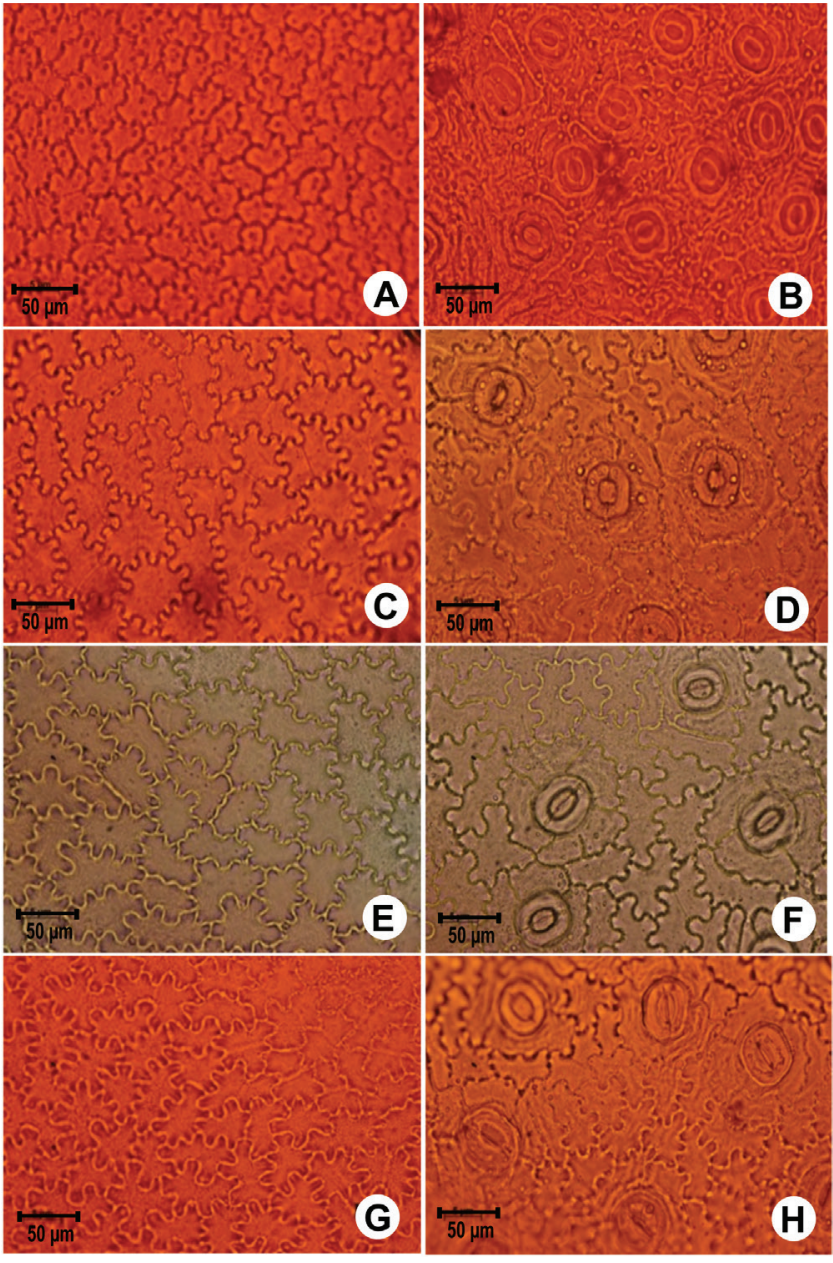

Figure 5. Epidermal cells on the adaxial and abaxial side of the specimens' leaves: shape, size, anticlinal wall and stomata under light microscopy.(A, B) H. helix, (C, D) H. pastuchovii, (E, F) H. pastuchovii, and $(\mathrm{G}, \mathrm{H}) \mathrm{H}$. pastuchovii.

network, supporting the phylogenetic results that the Hedera is composed of two clades. Populations of H. helix $(1,2$ and 3$)$ are distinct and stand separately from the other

Table 5. Dataset and tree statistics from single analysis of the nuclear region.

\begin{tabular}{ll}
\hline Total sample & nrDNA ITS \\
\hline Number of sequences & 13 \\
Number of ingroup sequences & 11 \\
Alignment length [bp] & 602 \\
Number of parsimony- informative characters & 56 \\
Number of MPTs & 16 \\
Length of MPTs & 74 \\
Consistency index (Cl) & 0.98 \\
Retention index (RI) & 0.87 \\
Evolutionary model selected (under AIC) & $\mathrm{GTR}+\mathrm{G}$ \\
\hline
\end{tabular}




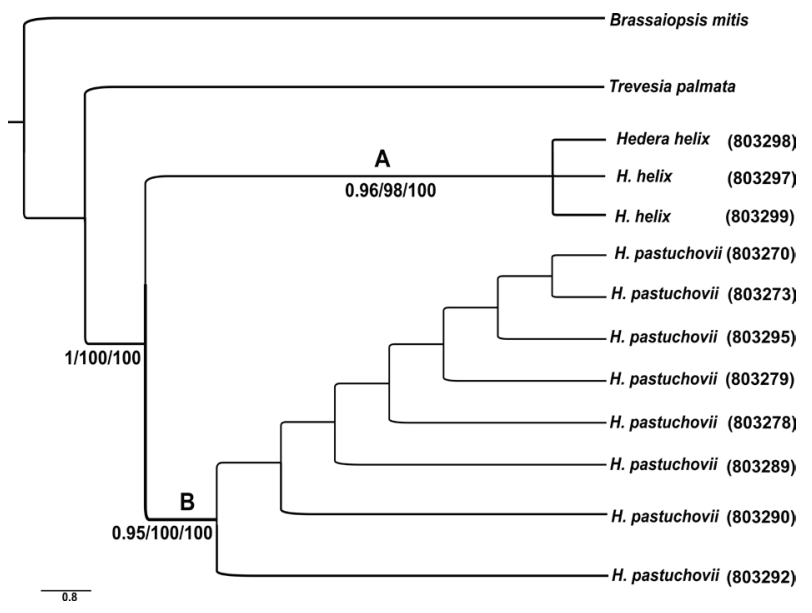

Figure 6. Consensus tree ( $50 \%$ majority rule) resulting from the Bayesian phylogenetic analysis of the nrDNA ITS dataset. Numbers of the branches are posterior probability (PP) from the $\mathrm{BI}$ and bootstrap support (BS) values from a MP and ML analysis, respectively (values $<50 \%$ were not shown).

populations at a major distance. The groups formed in the splits graph are readily correlated to the clades recovered in the phylogenies. We use the term "lineage" to refer to groups of populations in the NN diagram (Fig. 7), and "clade" to refer to groups in the phylogenies (Fig. 6). The ITS splits graph revealed two main groups (Fig. 7). One of these, lineage "I" correlates to clade "A" in Fig. 6 and is composed of populations of H. helix. The later, lineage "II" that is includes the populations of $H$. pastuchovii, corresponding to clade "B" in Fig. 6. Populations of $H$. pastuchovii (4-11) show a more near genetic affinity and are placed close to each other (Fig. 7).

\section{Discussion}

Hedera has gained little attention in previous micromorphological and phylogenetic studies, hence, this study presents the first comprehensive investigation of this genus in Iran. Our achievement provides statistical support for the recognition of two species as well as the two major groups traditionally recognized in Hedera based on trichomes: the stellate group $(H$. helix) and the scale-like group (H. pastuchovii) in agreement with Valcárcel and Vargas (2010). Natural distribution of H. helix is Europe and ploidy level and somatic chromosome number of it is $2 \mathrm{n}=2 \mathrm{x}=48$. Whereas $H$. pastuchovii distributed mainly in Caucasus, Iran and Afghanistan with $2 \mathrm{n}=6 \mathrm{x}=144$ somatic chromosome number. In general, it can be concluded that, reproductive traits such as pollen and seed traits have achieved the end of their evolution and are valuable in systematic studies. Pollen grains of $H$. helix are smaller rather than $H$. pastuchovii. This is consistent with their different ploidy level that $H$. helix is diploid ( $2 \mathrm{n}$ $=2 \mathrm{x}=48)$, whereas H. pastuchovii is hexaploid $(2 \mathrm{n}=6 \mathrm{x}=$ 144) (Valcárcel and Vargas 2010).

In consistence with finding of Savulescu and Luchian (2009), our results show that epidermis is made up of only one cells layer with polygonal cells with thin lateral walls and corrugated. Stomata are present on the lower (abaxial) surfaces of leaves only. Locality and habitats of the species also significantly affect the stomata density. Hedera helix occupies forest and open woodlands with high humidity. In woodland habitats, it frequently forms a dense ground cover occupying large areas and made up of many individuals (Metcalfe 1958). So high stomata density was observed in $H$. helix and low density in $H$. pastuchovii. Two species demonstrated an anemocytic type of stomata. Stomata have a significant role as valuable differentiating characters at different levels of plant ecology, taxonomy and physiology. Furthermore, the stomata type, density and structure may affect plant physiology, water efficiency and biomass (Luo and Zhou 2001). Humidity in the forest areas can affect the stomata density because the plants do not suffer from drought in such areas. Generally, plants have different strategies to cope with ecological factors. The findings in the current study are in accord with those in other studies relating to the stomata and structure (Miller 1983).

Plant molecular studies chiefly advanced in the recent years and molecular phylogenetic investigation has dramatically alternated our views of organismal relationships (Soltis and Soltis 2000). Nuclear molecular technique has been successfully used for research of infraspecific variations in different genera (Sheidai et al. 2013, 2014). Therefore, we decided to use the molecular approach for research of infra-specific variations between Hedera species. The results of molecular studies based on nuclear DNA sequence data are congruent with taxonomy.

Phylogenetic analyses indicated the monophyly of Hedera with strongly support $(\mathrm{PP}=1.00, \mathrm{ML} / \mathrm{BS}=$ $100 / 100$ ) and divided into two major clades. Our result is also in concordance with Vargas et al. (1999) and that

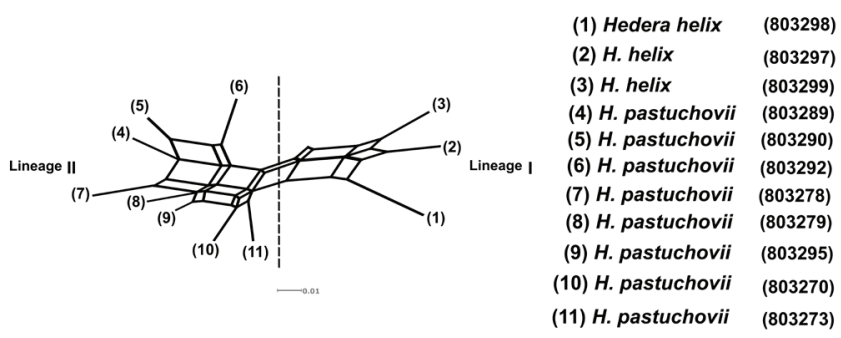

Figure 7. NeighborNet for ITS sequences of Hedera. Two major groups were recovered (i.e., lineage I and lineage II). 
in their analysis $H$. helix is belonging to diploid clade and H. pastuchovii is nested in polyploid clade. Molecular study (nrDNA ITS and trnT-L sequences) conducted by Valcárcel and Vargas (2012), did not confirm any close relationship between $H$. helix and $H$. pastuchovii. Thus, it is maybe due to variable levels of polyploidy and low gene flow between these two species. Even though, we confirm the monophyly of the genus Hedera relationships among populations of each species in clades $\mathrm{A}$ and $\mathrm{B}$, were poorly resolved and form a polytomy. NeighborNet analysis of data set displayed a clear correlation between genetic clusters and geographical groups as natural distribution of $H$. helix is Europe, Whereas H. pastuchovii distributed mainly in Asia. Geographical distribution of genetic diversity is also consistent with this cytotaxonomic diversity pattern as the highest genetic diversity is found in the Mediterranean basin while other areas have lower levels of genetic diversity (Vargas et al. 1999; Grivet and Petit 2002; Ackerfield and Wen 2003; Valcárcel et al. 2003; Valcárcel 2008; Green et al. 2011).

In conclusion, present study was carried out to provide additional evidence for taxonomists. These taxa differ in taxonomically important micromorphological and molecular characteristics. Generally, statistical and bioinformatics tests revealed the great difference between two species. In fact, sequence divergence among populations of each species was generally low, resulting in a lack of phylogenetic resolution, so it is necessary to use chloroplast markers and some other molecular techniques useful at the population level for example AFLP, ISSR, microsatellites to better resolve the relationships between the populations of one species. A number of fast evolving genes will be necessary for resurrecting subspecies or verities in these two species.

\section{Acknowledgements}

The authors would like to thank Razi Institute (Tehran, Iran) staff for their assistance in scanning electron microscope, and all of persons who helped us in this research work. The present study was financially supported by Gonbad Kavous University.

\section{References}

Ackerfield J, Wen J (2002) A morphometric analysis of Hedera L. (the ivy genus, Araliaceae) and its taxonomic implications. Adansonia 324:197-212.

Ackerfield J, Wen J (2003) Evolution of Hedera (the ivy genus, Araliaceae): insights from chloroplast DNA data. Int J Pl Sci 164:593-602.
Amini E, Nasrollahi F, Sattarian A, Khormali A, Habibi M (2019) Micro-morphological and molecular study of four species of Lonicera (Caprifoliaceae) in Iran. Phytol Balc 25(2):181-190.

Amini E, Kazempour-Osaloo Sh, Maassoumi AA, ZareMaivan H (2018) Phylogeny, biogeography and divergence times of Astragalus section Incani DC. (Fabaceae) inferred from nrDNA ITS and plastid $r p l 32-t r n \mathrm{~L}_{(\mathrm{UAG})}$ sequences. Nord J Bot 37. DOI: 10.1111/njb.02059.

Amini E, Nasrollahi F, Sattarian A, Kor S, Boozarpour S (2018) Molecular and micro-morphological evidences of the genus Cuscuta in Iran. Rostaniha 19:113-129.

Baldwin BG, Sanderson MJ, Porter JM, Wojciechowski MF, Campbell CS, Donoghue MJ (1995) The ITS region of nuclear ribosomal DNA: a valuable source of evidence on angiosperm phylogeny. Ann Missouri Bot Gard 82:247-277.

Baldwin BG (1992) Phylogenetic utility of the internal transcribed spacers of nuclear ribosomal DNA in plants: An example from the Compositae. Mol Phyl Evol 1:3-16.

Browicz K (1973) Hedera. In Rechinger KH, ed., Flora Iranica. Akademische Druck-U. Verlagsanstalt, Graz, Austria. 1-4.

Bryant D, MoultonV (2004) NeighborNet: An agglomerative method for the construction of phylogenetic networks. Mol Biol Evol 21:255-265.

Chase MW, Soltis DE, Olmstead RG, Morgan D, Les DH, Mishler BD, Duvall MR, Price RA, Hills HG, Qiu Y-L, Kron KA, Rettig JH, Conti E, Palmer JD, Manhart JR, Sytsma KJ, Michaels HJ, Kress WJ, Karol KG, Clark WD, Hedren M, Gaut BS, Jansen RK, Kim KJ, Wimpee CF, Smith JF, Furnier GR, Strauss SH, Xiang Q-Y, Plunkett GM, Soltis PS, Swensen SM, Williams SE, Gadek PA, Quinn CJ, Eguiarte LE, Golenberg E, Learn GH, Jr, Graham SW, Barrett SCH, Dayanandan S, Albert VA (1993) Phylogenetics of seed plants: an analysis of nucleotide sequences from the plastid gene rbcL. Ann Missouri Bot Gard 80:528-580.

Edgar RC (2004) Muscle: Multiple sequence alignment with high accuracy and high throughput. Nucl Acids Res 32:1792-1797.

Erdtman G (1952) Pollen Morphology and Plant Taxonomy. Angiosperms. Chronica Botanica Co., Waltham, Massachusettes. Copenhagen.

Erdtman G, Praglowski J, Nilsson S (1963) An Introduction to a Scandinavian Pollen Flora II. Almqvist and Wiksell, Uppsala, 89 pp.

Felsenstein J (1985) Confidence limits on phylogenies: An approach using the bootstrap. Evolution 39:783-791.

Green AF, Ramsey TS, Ramsey J (2011) Phylogeny and biogeography of Ivies (Hedera spp., Araliaceae), a polyploid complex of woody vines. Syst Bot 36:1114-1127.

Grivet D, Petit RJ (2002) Phylogeography of the common ivy 
(Hedera sp.) in Europe: genetic differentiation through space and time. Mol Ecol 11:1351-1362.

Hammer O, Harper DAT, Ryan PD (2001) PAST: Paleontological statistics software package for education and data analysis. Palaeontol Electron 4:1-9.

Huson DH, Bryant D (2006) Application of phylogenetic networks in evolutionary studies. Mol Biol Evol 23:254-267.

Ingrouille MJ (1986) The construction of cluster webs in numerical taxonomic investigation. Taxon 35:541-545.

Lawrence GHM, Schulze AE (1942) The cultivated Hederas. Gentes Herbarum 6:107-173.

Lowry PP II, Plunkett GM, Wen J (2001) Generic relationships in Araliaceae: looking into de crystal ball. S African J Bot 70:382-392.

Lum C, Maze J (1989) A multivariate analysis of the trichomes of Hedera L. Watsonia 17:409-418.

Luo Y, Zhou ZK (2001) Cuticle of Quercus sugen. Cyclobalanopsis (Oerst.) Chneid. (Fagaceae). Acta Phytophysiol Sin 39:489-501.

Mabberley DJ (1997) The Plant-book. A portable dictionary of the vascular plants. Cambridge University Press, Cambridge.

McAllister HA (1982) New work on ivies. Int Dendrol Soc 1981:106-109.

McAllister HA (1988) Canary and Algerian ivies. The Plantsman 10:27-29.

McAllister HA, Rutherford A (1990) Hedera helix L. and H. Hibernica (Kirchner) bean (Araliaceae) in the British Isles. Watsonia 18:7-15.

Metcalfe DJ (1958) Hedera helix L. Biological Flora of The British Isles. List Br Vasc Pl, No. 268.

Metcalfe CR, Chalk L (1985) Anatomy of Dicotyledons. Vols I and III. Oxford University Press.

Meusel H, Jäger E, Weinert E (1965) Vergleichende Chorologie der Zentraleuropäischen Flora. Veb Gustav Fischer Verlag, Jena.

Miller EC (1983) Plant Physiology. McGrow Hill Book Company, New York, USA.

Miller MA, Pfeiffer W, Schwartz T (2010) Creating the CIPRES Science Gateway for Inference of Large Phylogenetic Trees. Proceedings of the Gateway Computing Environments Workshop (GCE), New Orleans, Louisiana. Piscataway: IEEE. 45-52.

Naderi Safar K, Kazempour-Osaloo Sh, Maassoumi AA, Zrre Sh (2014) Molecular phylogeny of Astragalus section Anthylloidei (Fabaceae) inferred from nrDNA ITS and plastid rpl32-trn $\mathrm{L}_{(\mathrm{UAG})}$ sequence data. Turkish J Bot 38:637-652.

Nasrollahi F, Kazempour-Osaloo Sh, Saadati N, Mozaffarian V, Zare-Maivan H (2019) Molecular phylogeny and divergence times of Onosma (Boraginaceaes.s.) based on nrDNA ITS and plastid $r p l 32-t r n \mathrm{~L}_{(\mathrm{UAG})}$ and $t r n \mathrm{H}-p s b \mathrm{~A}$ sequences. Nordic J Bot, DOI: 10.1111/njb.02060.
Nylander JAA (2004) MrModeltest v2. Program distributed by the author. Evolutionary Biology Centre. Uppsala University, Uppsala.

Page DM (2001) Tree View (Win32) version 1.6.6. Available: http://taxonomy.zoology.gla.ac.uk/rod/treeview.html.

Plunkett GM, Wen J, Lowry PP II (2004) Infrafamilial classifications and characters in Araliaceae: insights from the phylogenetic analysis of nuclear (ITS) and plastid (trnL-trnF) sequence data. Plant Syst Evol 245:1-39.

Pojarkova AI (1951) The Chinese species of ivy and their taxonomic and geographic connections. Nat Syst ex Herb Bot nom V.L. Komarovii Acad Sci URSS XIV, 224-264.

Posada D, Buckley TR (2004) Model selection and model averaging in phylogenetics: Advantages of akaike information criterion and Bayesian approaches over likelihood ratio tests. Syst Biol 53:793-808.

Punt W, Reitsma TJ, Reuvers AAML (1976) The Northwest European pollen flora, 2. Caprifoliaceae. Rev Palaeobot Palynol 17:5-29.

Punt W, Hoen PP, Blackmore S, Nilsson S, Thomas AL (2007) Glossary of pollen and spore terminology. Rev Palaeobot Palynol 143:1-81.

Ronquist F, Teslenko M, van der Mark P, Ayres DL, Darling A, Höhna S, Larget B, Liu L, Suchard MA, Huelsenbeck JP (2012) MrBayes 3.2: efficient Bayesian phylogenetic inference and model choice across a large model space. Syst Biol 61:539-542.

Rutherford A (1984) The history of the Canary Islands ivy and its relatives. Ivy J 10:13-18.

Rutherford A (1989) The ivies of Andalusia (Southern Spain). Ivy J 15:7-17.

Rutherford A, McAllister HA, Mill RR (1993) New ivies from the Mediterranean area and Macaronesia. The Plantsman 15:115-128.

Sang T, Crawford DJ, Stuessy T (1995) Documentation of reticulate evolution in peonies (Paeonia) using internal transcribed spacer sequences of nuclear ribosomal DNA: Implication for biogeography and concerted evolution. Proc Natl Acad Sci USA. 92:6813-6817.

Savulescu E, Luchian V (2009) Comparative anatomy of the vegetative organs of the Hedera helix. (Araliaceae). Sci Papers, USAMV Bucharest, Ser A, Vol LII.

Seemann B (1868) Revision of the Natural Order Hederaceae. L Reeve and Co., London.

Sheidai M, Zanganeh S, Haji-ramezanali R, Nouroozi M, Noormohammadi Z, Ghsemzadeh-baraki S (2013) Genetic diversity and population structure in four Cirsium (Asteraceae) species. Biologia 68:384-397.

Sheidai M, Ziaee S, Farahani F, Talebi SY, Noormohammadi Z, Hasheminejad-Ahangarani-Farahani Y (2014) Infraspecific genetic and morphological diversity in Linum album (Linaceae). Biologia 69:32-39.

Soltis DE, Soltis PS (2000) Contributions of plant molecular 
systematics to studies of molecular evolution. Plant Mol Biol 42:45-75.

Swofford DL (2002) PAUP*: Phylogenetic Analysis Using Parsimony (*and Other Methods), Version 4.0b10. Sunderland: Sinauer Associates.

Tobler F (1912) Die Gattung Hedera. Gustav Fischer, Jena.

Valcárcel V (2008) Taxonomy, systematics and evolution of Hedera L. (Araliaceae). Ph.D. dissertation, Universidad Pablo de Olavide, Sevilla, Spain (English/Spanish).

Valcárcel V, Vargas P (2012) Phylogenetic reconstruction of key traits in the evolution of ivies (Hedera L.). Plant Syst Evol, DOI: 10.1007/s00606-012-0734.

Valcárcel V, Fiz O, Vargas P (2003) Chloroplast and nuclear evidence for multiple origins of polyploids and diploids of Hedera (Araliaceae) in the Mediterranean basin. Mol Phylogenet Evol 27:1-20.

Valcárcel V, Vargas P (2010) Quantitative morphology and species delimitation under the general lineage concept: optimization for Hedera (Araliaceae). Amer J Bot 97:1555-1573.
Valcárcel V, Fiz-Palacios O, Wenc J (2014) The origin of the early differentiation of Ivies (Hedera L.) and the radiation of the Asian Palmate group (Araliaceae). Mol Phylogenet Evol 70:492-503.

Van Helvoort HAM, Punt W (1984) The Northwest European Pollen Flora, 29. Araliaceae. Rev Palaeobot Palynol 42:1-5.

Vargas P, McAllister HA, Morton C, Jury SL, Wilkinson MJ (1999) Polyploid speciation in Hedera (Araliaceae): phylogenetic and biogeographic insights based on chromosome counts and ITS sequences. Pl Syst Evol 219:165-179.

Wen J, Plunkett GM, Mitchell AD, Wagstaff SJ (2001) The evolution of Araliaceae: a phylogenetic analysis based on ITS sequences of nuclear ribosomal DNA. Syst Bot 26:144-167.

White TJ, Bruns T, Lee S, Taylor J (1990) Amplification and direct sequencing of fungal ribosomal RNA genes for phylogenetics. In Innis MA, Gelfand DH, Sninsky JJ, White TJ, eds, PCR Protocols: A Guide to Methods and Applications. Academic Press, San Diego. 315-322. 
